\title{
Carbon footprint estimation for a sustainable improvement of supply chains: state of the art
}

\author{
Pilar Cordero \\ Universitat Politècnica de València (Spain) \\ mpilar.cordero@gmail.com
}

Received: September 2012

Accepted: March 2013

\section{Abstrac:}

Purpose This paper examines the current methodologies and approaches developed to estimate carbon footprint in supply chains and the studies existing in the literature review about the application of these methodologies and other new approaches proposed by some authors.

Design/methoddogy/approadr Literature review about methodologies developed by some authors for determining greenhouse gases emissions throughout the supply chain of a given sector or organization.

Findings and Originality/value Due to its usefulness for the design and management of a sustainable supply chain management, methodologies for calculating carbon footprint across the supply chain are recommended by many authors not only to reduce GHG emissions but also to optimize it in a cost-effective manner. Although these approaches are in first stages of development and the literature is scarce, different methodologies for estimating CF emissions which include EIO analysis models and standardized methods and guidance have been developed, some of them applicable to supply chains especially methodologies for calculating CF of a specific economic sector supply chain in a territory or country and for calculating CF of an organization applicable to the estimation of GHG emissions of a specific company supply chain.

Keywords: supply chain, carbon footprint, sustainability, organization 


\section{Introduction}

Supply Chain Management (SCM) encompasses the planning and management of all activities involved in sourcing and procurement, conversion, and all logistics management activities (Council of Supply Chain Management Professionals, 2012) which report economic benefits to companies. However, despite being economically feasible, these supply chain are not sustainable, because the can have a negative impact in relation to environmental and social aspects. Thus, the concept of Sustainable Supply Chain Management (SSCM) have emerged in recent years as the strategic, transparent integration and achievement of an organization's social, environmental and economic goals in the systemic coordination of key interorganizational business processes for improving the long-term economic performance of the individual company and its supply chains (Mentzer, DeWitt \& Keebler, 2001; Lambert, 2006; Carter \& Rogers, 2008). The literature review shows some initiatives to improve the sustainability performance of supply chains is context: Svensson (2007) identifies several sustainable business practices in supply chains such as corporate social responsibility, green purchasing strategies, environmental purchasing, reverse logistics, environmental management, life cycle assessment and ISO 14000 certifications among others.

In order to measure and compare the most significant environmental impacts along the supply chains as well as the improvements achieved with the implementation of these initiatives, is necessary methods and tools. There are many approaches to study the environmental (Finnveden \& Moberg, 2005) and sustainability aspects of production and consumption (Ness, Urbel-Piirsalu, Anderberg \& Olsson, 2007): qualitative approaches such as industrial ecology, design for environment, and cleaner production and other approaches based on quantitative models, e.g., material flows accounting and strategic environmental assessment and Life Cycle Assessment (LCA), (Heijungs, Huppes \& Guinée, 2010) being this tool the most established and well-developed tool in this category (Ness et al., 2007). Due to the increasing concern about global climate change and carbon emissions as a casual factor (Rotz, Montes \& Chianese, 2010), the term Carbon footprint has become popular over the last few years. Carbon footprint (CF) is a procedure that is referred to the quantity of greenhouse gases (carbon dioxide, methane, nitrous oxide and halocarbons) produced during product's life cycle (Pihkola, Nors, Kujanpää, Helin, Karimiemi, Pajula et al., 2010). In fact, CF could be considered as a simplified version of LCA Analysis in which, instead of considering all environmental impacts categories, only the environmental impact category Global Warming is considered. Concerning supply chains, many researchers agreed the efficiency of carbon management strategies from the point of view of the organization, helping decision makers to achieve sustainability objectives identifying key points in the supply chain, potential risks, and opportunities of improvement (Carballo-Penela \& Domenech, 2010) in a cost-effective manner in the design of a green supply chain (Finkbeiner, 2009; Pandey, Agrawal \& Pandey, 2010; Hua, Cheng \& Wang, 2011; Lee, 2011) such the use of energy-efficient vehicles, waste reduction through process optimization and recycling (Sundarakani, de Souza, Goh, Wagner, 
Manikandan, 2010) and from the point of view of consumers, CF can be seen as a subset of the demand for environmental information that is being used for knowledge-based decision making in the context of sustainable consumption and production (Carballo-Peneda \& Domenech, 2010).

This paper examines the current methodologies and approaches developed to estimate CF in supply chains and the studies existing in the literature review about the application of these methodologies and other new approaches proposed by some authors in order to get an overview of the using this approach to the environmental improvement of supply chains.

\section{Carbon Footprint methodologies}

\subsection{General methodologies for calculating Carbon Footprint}

In general, methodologies for calculating $\mathrm{CF}$ can be classified into the following types (Wiedmann \& Minx, 2008; IHOBE, 2009)

- Methodologies for calculating CF of a territory or country, used for the preparation of emission inventories. These emission inventories are generally calculated through a methodology called Input-output analysis (EIO).

- Methodologies for calculating CF of an organization (or Corporate CF methodologies) which identify emissions from all the activities across the organization, including buildings' energy use, industrial processes and company vehicles.

- Methodologies for calculating CF of a product or service which identify emissions over the whole life of a product or service, from the extraction of raw materials and manufacturing right through to its use and final reuse, recycling or disposal.

Both corporate and product CF methods are generally based on LCA-based approaches. Table 1 shows some initiatives and methodological standards (or drafts thereof) and guidances to estimate CF associated with products and organizations. Some of these methodologies, generally corporate CF methodologies such as Greenhouse Gas Protocol (GHG Protocol) (2012), distinguishes three scopes of carbon emissions: direct GHG emissions (Scope 1), electricity indirect GHG emissions (Scope 2), and other indirect GHG emissions (Scope 3) (Lee, 2011). Because Scopes 1 and 2 footprints are generally less than 25\% of the total direct and upstream footprint for a vast majority of businesses, Scope 3 such as indirect emissions from purchased and sold products that should not be ignored as knowledge of them can help inform more holistic approaches to address life cycle footprint across the supply chain (Huang, Weber \& Matthews, 2009; Lee, 2011) (Figure 1). 


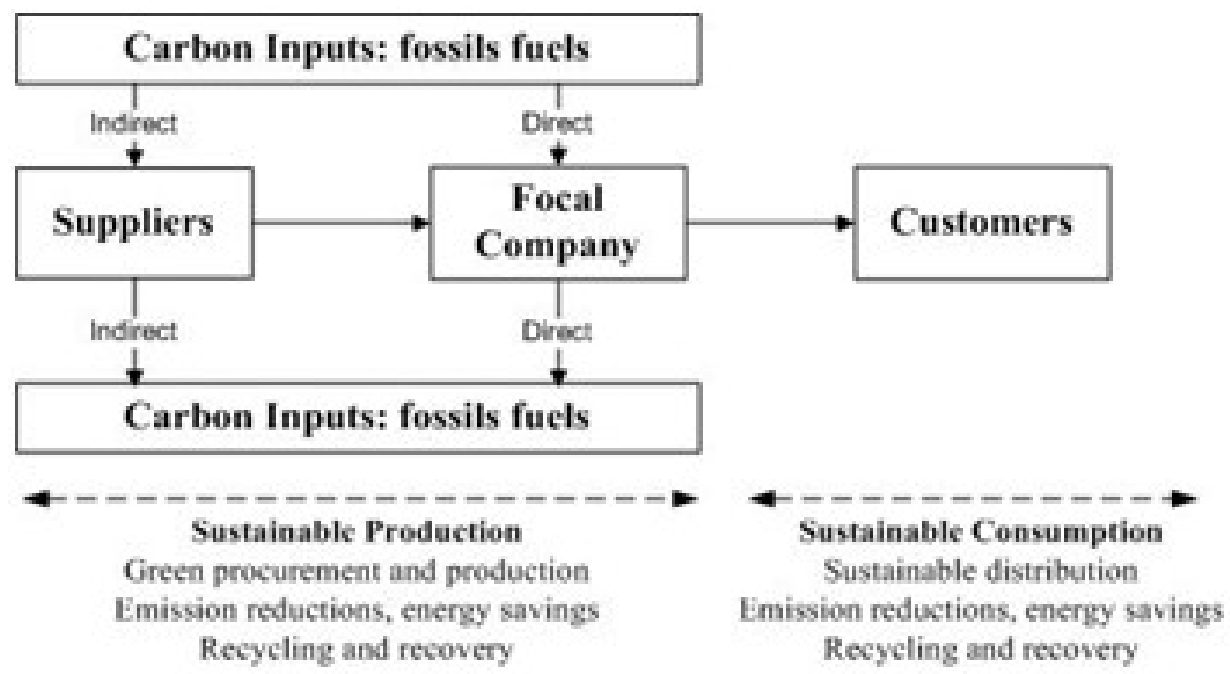

Figure 1. Direct vs. indirect effects of CF in the supply chain. (Lee, 2011)

\begin{tabular}{|c|c|c|c|c|}
\hline Scope & Developed by & Standard/Methodology & Product & Corporate \\
\hline \multirow[t]{6}{*}{ International } & \multirow[t]{3}{*}{ GHG Protocol } & $\begin{array}{l}\text { Corporate Acounting and } \\
\text { Reporting Standards }\end{array}$ & & $x$ \\
\hline & & $\begin{array}{l}\text { Project Accounting Protocol } \\
\text { and Guidelines }\end{array}$ & & $x$ \\
\hline & & Product Standards & $x$ & \\
\hline & \multirow[t]{3}{*}{ ISO } & ISO $14064-1$ & & $x$ \\
\hline & & ISO 14067 & $x$ & \\
\hline & & ISO 14069 & & $x$ \\
\hline Europe & $\begin{array}{l}\text { European } \\
\text { Commission }\end{array}$ & $\begin{array}{l}\text { Corporative and product } \\
\text { Carbon Footprint }\end{array}$ & $x$ & $x$ \\
\hline UK & $\begin{array}{l}\text { British Standard } \\
\text { Institutions (BSI) }\end{array}$ & $\begin{array}{l}\text { UK's Product Carbon } \\
\text { Footprint (PAS 2050) }\end{array}$ & $x$ & \\
\hline \multirow[t]{2}{*}{ France } & AFNOR & BP $\times 30-323$ & $x$ & \\
\hline & ADEME & Bilan Carbone & & $x$ \\
\hline Sweden & SEMCO & EPD System & $x$ & \\
\hline Japan & JISC & TS Q 0010 & $x$ & \\
\hline
\end{tabular}

Table 1. Examples of methodologies and approaches for calculating CF of products and organizations (European Commission, 2011; Finkbeiner, 2009; Pandey, Agrawal \& Pandey, 2010)

\subsection{Experiences in the application of Carbon Footprint methodologies in supply chains}

While green supply chain management has become popular, fewer studies have been published on CF in supply chain management (Lee, 2011). The studies founded in the literature generally show the application of EIO models for estimating CF of some specific sector in a territory or country and the application of methods for estimating CF of some specific organization supply chain listed above and the proposal of new carbon modeling approaches to be applied in the design and managements of supply chains. Table 2 shows a summary of the most relevant studies available in the literature. 
Application of EIO analysis for estimating CF of some specific sector in a territory or country

\begin{tabular}{|c|c|}
\hline Minx et al. (2008) & $\begin{array}{l}\text { Application of input-output model to identify GHG emission hotspots in the } \\
\text { international supply chain of two food products (meats and oils) }\end{array}$ \\
\hline Wiedmann and Minx (2008) & Discussion of the advantages of the use of hybrid-EIO-LCA approaches \\
\hline Huang et al. (2009) & Application of hybrid EIO-LCA approaches in the electronic sector \\
\hline Virtanen et al. (2011) & Application of the hybrid-EIO-LCA approach in Finnish food chain \\
\hline \multicolumn{2}{|c|}{ Application of existing methodologies for estimating CF in some specific organization supply chain } \\
\hline Lee $(2011)$ & $\begin{array}{l}\text { Integration of carbon emissions in automobile supply chain management by } \\
\text { using GHG Protocol }\end{array}$ \\
\hline Carbon Trust (2006) & $\begin{array}{l}\text { Development of a business tool for carbon management across the supply chain } \\
\text { of a specific organization }\end{array}$ \\
\hline Rizet et al. (2012) & $\begin{array}{l}\text { Application of Bilan Carbone methodology to compare energy consumption and } \\
\mathrm{CO}_{2} \text { emissions of supply chains in Belgium, France and UK considering different } \\
\text { products: jeans, yogurts, apples, tomatoes and furniture }\end{array}$ \\
\hline $\begin{array}{l}\text { Espinoza-Orias, Stichnothe \& } \\
\text { Azapagic (2011) }\end{array}$ & $\begin{array}{l}\text { Comparison of CF in bread supply chain by using PAS } 2050 \text { and ISO } 14044 \\
\text { methodologies }\end{array}$ \\
\hline \multicolumn{2}{|r|}{ Other approaches } \\
\hline $\begin{array}{l}\text { Sundarakani, de Souza, Goh, } \\
\text { Wagner \& Manikandan (2010) }\end{array}$ & $\begin{array}{l}\text { Application of Eulerian and Lagrangian transport models in CF measurement in } \\
\text { a supply chain }\end{array}$ \\
\hline Milá i Canals et al (2011) & $\begin{array}{l}\text { Application of a meta-product-based accounting LCA approach for the } \\
\text { assessment and comparison of individual product types as well as for the } \\
\text { estimation of a brand's total GHG in a food company. }\end{array}$ \\
\hline $\begin{array}{l}\text { Carballo-Penela \& Doménech } \\
(2010)\end{array}$ & $\begin{array}{l}\text { Proposal of MC3 model as an internationally standardized method for the } \\
\text { assessment of GHG emissions to calculate CF of companies and organizations }\end{array}$ \\
\hline $\begin{array}{l}\text { Ramudhin, Chaabane, Kharoune } \\
\text { \& Paquet (2008) }\end{array}$ & $\begin{array}{l}\text { Proposal of a novel approach for Green Supply Chain Management (GSCM) by } \\
\text { tying GHGs emissions to carbon trading }\end{array}$ \\
\hline Benjaafar, Li \& Daskin (2010) & $\begin{array}{l}\text { Proposal of a series of model formulations that illustrate how carbon emissions } \\
\text { considerations can be incorporated into operations management models. }\end{array}$ \\
\hline Hua, Cheng \& Wang (2010) & $\begin{array}{l}\text { Management of CF in inventory management under the carbon emission trading } \\
\text { mechanism. }\end{array}$ \\
\hline
\end{tabular}

Table 2. Experiences in the application of CF methodologies in supply chains

EIO analysis have been considered by some authors to estimate CF emissions in some specific sector supply chains. Thus, Minx, Peters, Wiedmann and Barrett (2008) apply structural path analysis in a generalized multi-regional input-output model to identify GHG emission hotspots in the international supply chain of two food products (product groups) consumed in the UK (meats and oils) and Wiedmann and Minx (2008) discuss the advantage of the use of a hybridEIO-LCA approach, where life-cycle assessments are combined with input-output analysis that allows preserving the detail and accuracy of LCA-based approaches in lower order stages, while higher-order requirements are covered by the input-output part of the model. Huang et al. (2009) applied this methodology to estimate carbon footprint profiles of 8 electronics manufacturing and computer services sectors, by emphasizing the importance of considering indirect emissions (Scope 3 ) to focus their footprint efforts and Virtanen, Kurppa, Saarinen, Katajajauuri, Usva, Mäenpää et al. (2011) developed this model specifically for the Finnish food chain at the macro level. As far studies of the application of current methodologies for calculating CF in some specific organization supply chain is concerned, Lee (2011) proposes a new way to integrate carbon emissions in automobile supply chain management by using GHG 
Protocol. Carbon Trust (2006) has created a business tool for carbon management across the supply chain. This methodology has been successfully piloted with the supply chains of different newspaper and snack foods products. Rizet, Browne, Cornelis and Leonardi (2012) compares the energy consumption and $\mathrm{CO}_{2}$ emissions of supply chains in Belgium, France and UK looking in particular at, jeans, yogurts, apples, tomatoes and furniture considering Bilan Carbone methodology and Espinoza-Orias, Stichnothe and Azapagic (2011) makes a comparison of carbon footprint in bread supply chain in UK by using PAS 2050 and ISO 14044 methodologies. In the literature, some authors proposed new carbon modeling approaches to be applied in the design and managements of supply chains. Sundarakani et al. (2010) employ the Eulerian and Lagrangian transport models to calculate the emissions applied in models to study water quality, submarine outfalls, sediment erosion, oil dispersion and other types of pollution. Although, the application of this model in carbon footprint measurement in a supply chain has not been reported, authors find that it is an appropriate method of measurement because it considers both active and passive tracers in CF. Milá i Canals, Sim, García-Suárez, Neuer, Herstein, Kerr et al. (2011) apply a meta-product-based accounting LCA approach for the assessment and comparison of individual product types as well as for the estimation of a brand's total GHG in a food company due to a bottom-up product-based life cycle assessment (LCA) approach was considered impractical to assess company's portfolio's complexity. Carballo-Penela and Doménech (2010) developed MC3 an internationally standardized method for the assessment of GHG emissions from the life cycle of products built on the LCA guidance and key principles of relevant approaches of the field of LCA. All the data to estimate GHG emissions is obtained from the ledger accounts of the organization which allows a close relationship between the economic and the environmental aspect of the organization. On the other hand, Ramudhin, Chaabane, Kharoune and Paquet (2008) propose a novel approach for Green Supply Chain Management (GSCM) by tying GHGs emissions to carbon trading based on the called "Carbon Market Sensitive - Green Supply Chain Network Design" (CMS/GSCND). The proposed methodology is based on an integrated logistics mathematical model for green supply chain network design with GHGs emissions considerations. Benjaafar, Li and Daskin (2010) present a series of model formulations that illustrate how carbon emissions considerations can be incorporated into operations management models and Hua et al (2011) investigates how firms manage carbon footprints in inventory management under the carbon emission trading mechanism.

\section{Discussion}

Due to its usefulness for the design and management of a sustainable supply chain management, methodologies for calculating CF across the supply chain are recommended by many authors not only to reduce GHG emissions but also to optimize it in a cost-effective manner. In recent years different methodologies for estimating CF emissions have been developed some of them applicable to supply chains especially methodologies for calculating CF of a specific economic sector supply chain in a territory or country and for calculating CF of 
an organization applicable to the estimation of GHG emissions of a specific company supply chain. However these approaches are in first stages of development and the literature is scarce with respect to estimation of GHG emissions in different supply chain. Thus, the literature review shows some of these methodologies which include EIO analysis models and standardized methods and guidance such as developed by GHG Protocol as well as researches about their applicability to specific economic sectors and companies.

\section{References}

Benjaafar, S., Li, Y., \& Daskin, M. (2010). Carbon Footprint and the Management of Supply Chains: Insights from Simple Models. Retrieved $2^{\text {nd }}$ February 2012. http://www.isye.umn.edu/faculty/pdf/beyada-3-31-10.pdf

Carballo-Penela, A., \& Doménech, J.L. (2010). Managing the carbon footprint of products: the contribution of the method composed of financial statements (MC3). International Journal of Life Cycle Assesment, 15, 962-969. http://dx.doi.org/10.1007/s11367-010-0230-1

Carbon Trust (2006). Carbon Footprints in the Supply Chain: the next step for business. Retrieved $17^{\text {th }}$ February 2012. http://bit.ly/YOqPHV

Carter, C.R., \& Rogers, D.S. (2008). A framework for sustainable supply chain management: moving toward new theory. International Journal of Physical Distribution \& Logistics Management, 38(5), 360-387. http://dx.doi.org/10.1108/09600030810882816

Council of Supply Chain Management Professionals (2012). CSCMP Supply Chain Management Definitions. Retrieved $9^{\text {th }}$ January 2012. http://cscmp.org/aboutcscmp/definitions.asp.

Espinoza-Orias, N., Stichnothe, H., \& Azapagic, A. (2011). The carbon footprint of bread. International Journal of Life Cycle Assessment, 16,351-365. http://dx.doi.org/10.1007/s11367011-0271-0

European Commission (2011). Analysis of Existing Environmental Footprint Methodologies for Products and Organizations: Recommendations, Rationale, and Alignment. Retrieved $15^{\text {th }}$ February 2012. http://ec.europa.eu/environment/eussd/pdf/Deliverable.pdf

Finkbeiner, M. (2009). Carbon footprinting-Opportunities and threats. International Journal of Life Cycle Assessment, 14(2), 91-94. http://dx.doi.org/10.1007/s11367-009-0064-x

Finnveden, G., \& Moberg, A.. (2005). Environmental systems analysis tools e an overview. Journal of Cleaner Production, 13, 1165-1173. http://dx.doi.org/10.1016/j.jclepro.2004.06.004

Greenhouse Gas Protocol (GHG Protocol) (2012). Standards. Retrieved 2 $2^{\text {nd }}$ February 2012. http://www.ghgprotocol.org/ 
Heijungs, R., Huppes, G., \& Guinée, J.B. (2010). Life cycle assessment and sustainability analysis of products, materials and technologies. Toward a scientific framework for sustainability life cycle analysis. Polymer Degradation and Stability 95(3), 422-428. http://dx.doi.org/10.1016/j.polymdegradstab.2009.11.010

Hua, G., Cheng, T.C.E., \& Wang, S. (2011). Managing carbon footprints in inventory management. International Journal of Production Economics, 132, 178-185. http://dx.doi.org/10.1016/j.ijpe.2011.03.024

Huang, Y.A., Weber, C.L., \& Matthews, H.S. (2009). Carbon Footprinting Upstream Supply Chain for Electronics Manufacturing and Computer Services. Sustainable Systems and Technology, 2009. ISSST'09. IEEE International Symposium on 18-20 May 2009. http://dx.doi.org/10.1109/ISSST.2009.5156679

Lambert, D. (2006). Supply chain management: processes, partnerships, performance. Florida: The Hartley press.

Lee, K-H (2011). Integrating carbon footprint into supply chain management: the case of Hyundai Motor Company (HMC) in the automobile industry. Journal of Cleaner Production, 19, 1216-1223. http://dx.doi.org/10.1016/j.jclepro.2011.03.010

Mentzer, J.T., DeWitt, W., \& Keebler, J.S. (2001). Defining supply chain management. Journal of Business Logistics 22(2), 1-26. http://dx.doi.org/10.1002/j.2158-1592.2001.tb00001.x

Milá i Canals, L., Sim, S., García-Suárez, T., Neuer, G., Herstein, K., Kerr, C. et al. (2011). Estimating the greenhouse gas footprint of Knorr. International Journal of Life Cycle Assessment, 16(1), 50-58. http://dx.doi.org/10.1007/s11367-010-0239-5

Minx, J.C., Peters, G.P., Wiedmann, T., \& Barrett, J. (2008). GHG Emissions in the Global Supply Chain of Food Products. The 2008 International Input-Output Meeting on Managing the Environment (IIOMME), Seville, Spain, July 9-11.

Ness, B., Urbel-Piirsalu, E., Anderberg, S., \& Olsson, L. (2007). Categorising tools for sustainability assessment. Ecological Economics, 60(3), 498-508. http://dx.doi.org/10.1016/j.ecolecon.2006.07.023

Pandey, D., Agrawal, M., \& Pandey, J.S. (2010). Carbon footprint: current methods of estimation. Environmental monitoring and assessment, 178(1-4), 135-160. http://dx.doi.org/10.1007/s10661-010-1678-y

Pihkola, H., Nors, M., Kujanpää, M., Helin, T., Kariniemi, M., Pajula, T. et al. (2010). Carbon footprint and environmental impacts of print products from cradle to grave. Results from the 
LEADER project (Part 1). Retrieved $3^{\text {rd }}$ February 2012 http://www.vtt.fi/inf/pdf/tiedotteet/2010/T2560.pdf

Public Society of Environmental Management of the Basque Country (IHOBE) (2009). Life cycle assessment and carbon footprint. Two ways to estimate the environmental impacts of a product. Bilbao: IHOBE.

Ramudhin, A., Chaabane, A. , Kharoune, M., \& Paquet, M. (2008). Carbon Market Sensitive Green Supply Chain Network Design. Industrial Engineering and Engineering Management, 2008. IEEM 2008. IEEE International Conference on, Singapore, December 8-11. http://dx.doi.org/10.1109/IEEM.2008.4738039

Rizet, C., Browne, M., Cornelis, E., \& Leonardi, J. (2012).Assessing carbon footprint and energy efficiency in competing supply chains: Review - Case studies and benchmarking. Transportation Research Part D: Transport and Environment, 17(4), 293-300. http://dx.doi.org/10.1016/j.trd.2012.01.002

Rotz, C.A., Montes, F., \& Chianese, D.S. (2010). The carbon footprint of dairy production systems through partial life cycle assessment. Journal of Dairy Science, 93(3), 1266-1282. http://dx.doi.org/10.3168/jds.2009-2162

Sundarakani, B., de Souza, R., Goh, M., \& Wagner, S.M., Manikandan, S. (2010). Modeling carbon footprints across the supply chain. International Journal of Production Economics, 128(1), 43-50. http://dx.doi.org/10.1016/j.ijpe.2010.01.018

Svensson G. (2007). Aspects of sustainable supply chain management (SSCM): conceptual framework and empirical example. Supply Chain Management: An International Journal, 12(4), 262-266. http://dx.doi.org/10.1108/13598540710759781

Virtanen Y., Kurppa S., Saarinen M., Katajajuuri J-M, Usva K., Mäenpää I. et al. (2011). Carbon footprint of food - approaches from national input-output statistics and a LCA of a food portion. Journal of Cleaner Production, 19(16), 1849-1856. http://dx.doi.org/10.1016/j.jclepro.2011.07.001

Wiedmann, T., \& Minx, J. (2008). A Definition of 'Carbon Footprint'. In: C.C. Pertsova, Ecological Economics Research Trends. Hauppauge New York: Nova Science Publishers.

Journal of Industrial Engineering and Management, 2013 (www.jiem.org) 